\title{
AD OLESCENTE QUE CUMPRE MEDIDA SOCIOEDUCATIVA: modos de ser no cotidiano e possibilidades para enfermagem
}

\author{
Dilce Rejane Peres do CARM Oa, Stela M aris de M ello PAD OIN \\ Cristiane Cardoso de PAU LA ${ }^{c}$, M arlene G omes TER RA d, I vis E mília de Oliveira SOU ZA ${ }^{e}$
}

\section{RESUMO}

O bjetivou compreender o cotidiano do ser-adolescente que cumpre medida socioeducativa de semiliberdade. Investigação fenomenológica, desenvolvida em unidade da $\mathrm{F}$ undação de A tendimento Socioeducativo, no R io G rande do Sul. A entrevista foi desenvolvida com nove adol escentes, entre fevereiro e maio de 2009. A anál ise heideggeriana des-velou que vivenciar a medida socioeducativa significa uma prisão, algo ruim. Sabe que não está no sistema penitenciário por conta da idade e re-conhece que jogou fora sua adolescência. $\mathrm{Na}$ instituição vai à escola para aprender algo, para arrumar algum trabalho. M ostra-se no modo de ser do falatório, ambiguidade e ocupação. Conclui-se que o adolescente está-lançado naquilo que está determinado, mantém-se na impessoalidade. Para reinserção social precisa de ajuda do sistema socioeducativo, mediado pelo trabal ho interdisciplinar, rede de apoio de co-responsabilidade da família, comunidade e Estado.

D escritores: Saúde do adolescente. A dolescente institucional izado. F ilosofia em enfermagem.

\section{RESUMEN}

Se tuvo como objetivo comprender el cotidiano del ser adolescente que cumple medida socioeducativa de semilibertad. Investigación fenomenológica, desar rollada en una unidad de la F undación de A tención Socioeducativa, en R ío G rande del Sur, B rasil. L a entrevista fue desar rollada con nueve adol escentes, entre febrero y mayo de 2009. E I análisis heideggeriano desveló quevivenciar la medida socioeducativa significa una prisión, algo malo. E I adolescente sabe que no está en el sistema penitenciario debido a la edad y reconoce que echó a perder su adolescencia. E n la institución va a la escuela para aprender algo, para lograr algún trabajo. Se muestra en el modo de ser de la habladuría, ambigüedad y ocupación. Se concluye que el adolescente está lanzado en aquello que está determinado, se mantiene en la impersonalidad. Para su reinserción social necesita de la ayuda del sistema socioeducativo, mediado por el trabajo interdisciplinar, la red de apoyo de coresponsabilidad dela familia, comunidad y E stado.

Descriptores: Salud del adolescente. Adolescente institucionalizado. F ilosofía en enfermería.

T ítulo: A dol escente que cumple medida socioeducativa: modos de ser en el cotidiano y posi bilidades para la enfer mería.

\section{ABST RACT}

This study aimed to understand the routine of the adolescent- being, who is under semi-liberty socio- educational measures. A phenomenological research was developed in unit of the Socio- $E$ ducational $T$ reatment $F$ oundation ( $F$ undação deA tendimento Soci oeducativo), in the state of $\mathrm{R}$ io $\mathrm{G}$ rande do Sul, B razil. Interview $\mathrm{s}$ w ere held with nine adolescents, from $\mathrm{F}$ ebruary to $M$ ay, 2009. The H eideggerian analysis un-veiled that this socio-educational measure means a prison for them, something bad. T hey know they are not in the prison system due to their age and re cognize they have thrown away their adolescence. In the institution, these youngsters go to school to learn something, to get some job. They express themselves through gossip, ambiguity and occupation. The conclusion is that the teenager is-throw $n$ in that which is determined and remain in impersonality. F or social reintegration they need the hel p of the socio- educational system, mediated by interdisciplinary work, and a support netw ork for which the family, community and State are co-responsible

D escriptors: A dol escent health. A dolescent, institutionalized. P hilosophy, nursing.

T itle: A dol escents under socio-educational measures: everyday ways of being and possibilities for nursing.

\footnotetext{
a M estre em Enfermagem, Responsável Técnica do Serviço de Enfermagem da Unidade do Centro de Atendimento Socioeducativo de Internação, Santa M aria, Rio G rande do Sul, Brasil.

${ }^{b}$ D outora em Enfermagem, P rofessora A djunta do D epartamento de Enfer magem da U niversidade F ederal de Santa M aria (U F SM ), Santa Maria, Rio Grande do Sul, Brasil.

' D outora em Enfermagem, Professora A djunta do D epartamento de Enfermagem da UF SM, Santa M aria, Rio G rande do Sul, Brasil.

d D outora em Enfermagem, Professora Adjunta do D epartamento de Enfermagem da U F SM', Santa M aria, Rio Grande do Sul, Brasil.

e Doutora em Enfermagem, Professora T itular da E scola de Enfermagem A nna N ery da U niversidade Federal do Rio de Janeiro (EEAN -

UFRJ), Rio de Janeiro, Brasil.
} 


\section{INT RODUÇÃO}

As transformações biopsicossociais da fase do desenvolvimento da adolescência caracterizam um período de vulnerabilidade, no qual podem ocorrer alterações da personalidade, do comportamento e das relações. Essa vulnerabilidade também é resultado negativo da relação entre a disponibilidade dos recursos materiais ou simbólicos e o acesso à estrutura de oportunidades sociais, econômicas, culturais que provêm do Estado e da socieda$\mathrm{de}^{(1)}$.

D entre essa população que é considerada vulnerável, destaca-se 0 adolescente infrator e que cumpre medida socioeducativa (M SE). No Rio G rande do Sul (RS), 1.158 adolescentes estão em M SE de inter nação na F undação de A tendimento Sócio-E ducativo (FASE). D estes $43,3 \%$ estão em unidades do interior do Estado, 96,5\% são do sexo masculino, 79,2\% com idades entre 15 e 18 anos e $53,3 \%$ com escolaridade entre a 4a e 6a série do ensino fundamental. Quanto ao tipo de atos infracionais tem-se: roubo $(48,7 \%)$, homicídio $(12,5 \%)$ e tráfico de entorpecentes $(10,4 \%)^{(2)}$.

Há que se destacar alguns fatores que estão associados aos atos infracionais, e considerar que esses perpassam o conceito de vulnerabilidade, 0 qual nos remete a três planos interdependentes: individual, social e programático(3).

0 plano individual, que contempla os comportamentos, pode ser percebido pelo uso de drogas, comum a maioria dos adolescentes infratores. No Brasil, o álcool e a maconha são as drogas mais usadas pelo adolescente $e^{(4)}$. As drogas lícitas são usadas mais precocemente que as ilícitas, entre crianças e adolescentes institucionalizados a prevalência de experimentação e uso de drogas é al ta e precoce, acometendo a faixa etária entre 12 e 14 anos $^{(5)}$. 0 uso precoce dessas substâncias psicotrópicas poderá conduzir a problemas graves de comportamento, resultando na estreita a relação entre uso e abuso de álcool e de drogas ilícitas e delinquência $a^{(4,6-8)}$.

N esse contexto, o crack tem um poder infinitamente maior que as outras drogas de gerar dependência. A o prazer intenso e efêmero, segue-se a urgência da repetição. A lém de se tornarem alvo de doenças pulmonares e circulatórias que podem levar à morte, os usuários se expõem à violência e a situações de perigo que também podem matá- $\mid 0^{(9,10)}$.
0 plano social contempla que, na socialização primária, a família tem como principal proposição assegurar comportamentos normalizados pelo afeto e pela cultura. A qualidade do relacionamento familiar é um fator chave no encaminhamento do jovem para a delinquência ${ }^{(1,10)}$. D estaca-se a importância do resgate da figura paterna, defendendo, com base em estudos, que o comportamento antissocial, em qual quer membro da família, émais provável se o pai é ausente ou não participativo(11,12).

Tanto o comportamento pró-social quanto ao comportamento antissocial, são diretamente influenciados pelas interações. Os comportamentos vão se modificando pelo seu próprio desenvolvimento aliado às exigências do ambiente. A violência urbana, a qual é destacada como um dos principais problemas sociais no Brasil a exigir ações intersetoriais e multiprofissionais para sua prevenção, referese uma combinação de dificuldades precisas de relacionamentos na família e na sociedade ${ }^{(13,14)}$.

0 plano programático aponta para a existência de ações institucionais. 0 programa de execução das M SE de internação e de semiliberdade pretendem contribuir para a sua responsabilização e devolver-Ihe a capacidade de fazer suas escolhas a partir das suas possibilidades(15). Soma-se a necessidade de reconstrução sócio-político-econômica, dando ênfase à prevenção e ao tratamento das famílias. T alvez uma atenção adequada e eficaz junto aos adolescentes e seus familiares possa mesmo transformar realidades desesperançosas em oportunidades de vida que dêem abertura às possibilidades ${ }^{(10,16-18)}$.

Paralelo as demandas individuais, sociais e políticas da problemática apresentada, a produção do conhecimento na saúde do adolescente contempla na maioria dos estudos o enfoque epidemiológico, social, cultural e jurídico. No intuito de minimizar lacunas, este estudo lança um olhar à subjetividade e teve como questão norteadora: como é ser adolescente e estar cumprindo medida socioeducativa? Para tanto, o objetivo da pesquisa de mestrado foi compreender o cotidiano do adolescente que cumpre medida socioeducativa de semiliberdade.

\section{MATERIAIS E MÉTODO}

Investigação de natureza qualitativa, com abordagem fenomenológica e referencial teóricometodológico de Martin Heidegger ${ }^{(19)}$. Esta abor- 
dagem busca desvelar no objeto de estudo, a maneira como ele é em si mesmo, e não apenas o que é, ou seja, um saber do fenômeno e não somente sobre ele. Para tanto, suspende o conhecimento factual - o que já se sabe sobre os fatos - em busca da compreensão existencial do fenômeno. Desse modo, possibilita lançar um ol har ao adolescente em seu mundo próprio existencial, a fim de compreender sua singularidade de ser-no-mundo. Isso é possível por meio da intersubjetividade entre pesquisador e sujeito da pesquisa, na busca dos significados que os próprios sujeitos atribuem a sua vivência expressos em suas próprias palavras a partir do mundo da vida cotidiana, de sua bagagem de conhecimentos e de sua historicidade.

A etapa de campo da pesquisa foi desenvolvida mediante a aprovação do Comitê de É tica em Pesquisa da U niversidade Federal de Santa M aria/ RS (número do processo: 2008-31). 0 cenário da produção de dados foi uma unidade da FASE / RS, a qual é designada para cumprimento de M SE em regime de semiliberdade.

A inclusão para participação da pesquisa deuse pelos critérios: adolescentes na faixa etária de 12 a 18 anos (delimitação conforme o Estatuto da Criança e do A dolescente), que estavam cumprindo a medida socioeducativa de semiliberdade na unidade de atendimento da FASE do município que foi cenário da etapa de campo da pesquisa, e que não estavam sob suspeita de uso de drogas no período da produção dos dados (considerando a prerrogativa de que aos adolescentes em regime de semiliberdade realizam atividades na comunidade e, por vezes, tem acesso a oferta de drogas).

Os adolescentes tiveram sua inclusão mediante convite, durante a real ização de grupo operativo desenvolvido pela unidade. $\mathrm{D}$ eu-se a partir do termo de consentimento livre e esclarecido, o qual foi assinado pelo representante diretor da instituição, porque ele éo responsável legal pelo adolescente. Foi, também, assinado 0 assentimento livre e esclarecido pelo adolescente, demonstrando sua voluntariedade em participar da pesquisa.

0 modo de acesso aos adolescentes foi a entrevista fenomenológica. Essa modalidade possibilita dar conta do vivido do ser humano, tal como se apresenta na sua vivência, por meio de um movimento de compreensão. Como modo de acesso ao ser, a entrevista é desenvolvida como um encontro, singularmente estabel ecido entre o sujeito pesquisador e cada sujeito pesquisado. 0 encontro foi mediado pela empatia e intersubjetividade, mediante a redução de pressupostos ${ }^{(20)}$. Exigiu do pesquisador um posicionamento de des-centramento de si, para que se direcionar intencionalmente à compreensão dos adolescentes.

Durante 0 encontro, o pesquisador precisa: estar atento aos modos de se mostrar do sujeito entrevistado; captar o dito e o não dito; observar as outras formas de discurso: 0 silenciado, os gestos, as reticências e as pausas; e respeitar o espaço e tempo do outro. Essa posição de abertura do pesquisador ao outro possibilita aprimorar progressivamente a condução da entrevista. A entrevista iniciou-se pela questão orientadora: como é para você ser adolescente e estar cumprindo medida socioeducativa? No decorrer da entrevista a pesquisadora formulava por questões empáticas, a fim de evitar induzir respostas, mas destacando questões expressas pelos próprios adolescentes que precisavam ser aprofundadas para melhor compreensão dos possíveis significados apontados. Para encerrar a entrevista era desenvolvido um feedback, perguntando se 0 adolescente gostaria de acrescentar algo e agradecendo sua disposição-para esse encontro.

0 número de adolescentes não foi determinado previamente, visto que a etapa de campo mostrou a suficiência de significados expressos nas entrevistas, que possibilitaram responder ao objetivo da pesquisa. Então, com nove entrevistas findouse essa etapa, uma vez que os significados expressos nas entrevistas contemplaram as estruturas essenciais do fenômeno de investigação ${ }^{(20)}$.

A transcrição das entrevistas se deu conforme a fala original e foram apontados pela pesquisadora os silêncios e as expressões corporais observadas durante a entrevista. As entrevistas foram codificadas com a letra $A$ de adolescente seguidas dos números 1 a 9.

A análise contemplou o primeiro momento metódico heideggeriano: análise compreenssiva ${ }^{(19)}$. Constou da suspensão de pressupostos do pesquisador ao desenvolver a escuta e leitura atentivas das entrevistas, em busca de compreender o cotidiano do adolescente que cumpre M SE de semiliberdade, sem impor-Ihe categorias predeterminadas pelo conhecimento teórico/ prática. Foram sublinhadas, nas transcrições, as estruturas essenciais, compondo um quadro de análise. D este quadro foram constituídas as unidades de significação e 0 discurso fenomenológico, de modo a compor o con- 
ceito vivido, o qual é o fio condutor da interpretação(19).

\section{RESULTADOS E DISCUSSÃO}

A análise heideggeriana des-velou a compreensão do adolescente de que vivenciar a M SE significa uma prisão, algo ruim que el e tem que pagar, re-conhece que errou.

[ ...] eu sei que eu er rei, to pagando pelo meu er ro [ ...] sei que eu to er rado [ ...] pra vese eu consigo me melhora nédona, talvez fosseintébom eu sepreso [ silêncio] [ ...] (A 1).

[ ...] ruim nédona, porque fica sempre aqui, preso [ ...] Quem équevai quere fica preso? [ ...] (A5).

[ ...] gosta ninguém gosta, né dona; mais se tem que ta aqui; émelhor paga logo e sai pra não volta; [ ...] a gente, sabe que errou; [ ...] ninguém ta aqui, por que não fez nada [ risos] então é melhor paga tudo de uma vez $[\ldots](A 6)$.

[ ...] é certo se eu devo tem que paga né dona; eu to devendo o que eu fiz tem que paga pra eles [...] (A 9).

Revela o caráter socioeducativo da medida ao contar sobre a escola, os cursos na comunidade e ao saber que, após cumprir a M SE, ele vai "sair limpo" (sem registro judicial), acha que pode ser até bom ter sido preso, como possibilidade de "se melhorar". Sente-se mal, acha ruim acordar sempre no mesmo lugar.

[ ...] mesinto mau nédona, comé que o cara vai se senti bem, acorda sabendo que ta sempre no mesmo lugar [ ...] sai pra escola, curso; mais ainda ta preso [ ...] (A2).

M esmo realizando as atividades socioeducativas na comunidade e havendo a possibilidade de ir para casa nos finais de semana, el e se sente "preso". Estando em casa, é difícil voltar para a unidade, mas ele volta para pagar e "sair limpo".

[ ...] sai pra escola, curso, mas ainda ta preso [ ...] vai pra casa todo fim de semana, mas ta preso [ ...] (A2).

[ ...] éa primeira vez que eu caio preso. E u vou começa a sair, vou pra casa até que enfim [ se refere aos passeios de final de semana] [ ...] 0 brabo, vai ser voltar, mas eu volto, a juíza disse que se eu cumpri, paga tudo, fica tudo limpo, então tenho quevol ta [ ...] (A 3).
Revela seu envolvimento com drogas desde muito cedo, diz que as companhias e no grupo, estão às possibilidades de ter iniciado o uso - ao se juntar com outros adolescentes saía e "aprontava". A droga era uma escolha comum entre eles. Relata o uso de drogas como um fator gerador da MSE.

[ ...] dona eu usava droga né, lá fora [ ...] eu me juntava com os mano enós saia por aí, aprontar [ risos] , sedrogava e pronto [ ...] (A1).

[ ...] se ta com quem não usa, não usa [ drogas] , já com os cara a gurizada não que saber. A gora com crack ta ruim, eu cheguei aqui com 48 quilos, agora to gordo, com 62. N ão quero mais o crack, baseadinho, cigarro não vou dize que não [ ...] mas o cara depois não consegue mais sair [ ...] (A 3).

[ ...] comecei nessa vida [ ...] vendendo o bagulho [ ...] era cocaína [ ...] por isso que eu caí [ ...] tráfico e um porte [ ...] (A9).

Compreende-se que os adolescentes referemse ao mundo "lá fora", como que vivendo a M SE em um mundo a parte, regido por padrões de comportamento refletidos em seus modos de ser peculiar ao sistema que se apresenta a ele como prisão. E $m$ seu modo de ser no cotidiano mostram-se por meio do falatório(19).

Ao passar adiante o que todos dizem, não como forma de saber ou conhecer do que se fala, apenas para manter a comunicação, repetindo e passando adiante a fala, potencia-se a falta de solidez ${ }^{(19)}$.

No cotidiano revelado nas entrevistas, os discursos dos adolescentes se repetem como forma de afirmar-se nesse mundo do sistema socioeducativo. Publicar sua história de hábitos e vícios adquiridos parece explicar seu vivido na M SE. T alvez o adolescente possa ter sido mesmo influenciado pela sua historicidade, por um guiar-se a partir do que Ihe é familiar ${ }^{(19)}$.

$\mathrm{N}$ a maior parte das vezes, faz uso de drogas e pratica delitos para manter o consumo, reincidindo por vezes ao sistema. Ele justifica estar em M SE, devido ou apesar da sua tradição, isso é, o legado de uma tradição do passado, descrevendo seus modos de ser antes de estar em semiliberdade.

0 adolescente re-conhece que jogou fora sua adolescência. Reconhece o tempo da M SE como um tempo perdido, tempo que não vai voltar. 
[ ...] pra mim ta sendo ruim né dona porque eu só fico preso, não to aproveitando nada da minha adolescência, eu tinha meus amigo [ ...] (A9).

[...] aqui parece que o tempo não passa, e o tempo que não volta mais, vim pra cá com quinze, faz três anos, nesse vai e vem, nessa vida [ ...] (A5).

[ ...] tempo que não vai volta mais [ ...] vim pra cá com dezessete, to aqui há um ano e meio [ ...] (A 9).

0 adolescente se refere ao tempo do cumprimento da M SE, como um tempo perdido e que não volta mais. Sem dúvida, ele está se detendo ao tempo no sentido cronológico. No entanto, o conceito de temporalidade para o tempo, cujo significado é produzir em que o tempo precisa ser recuperado para o outro começo que está por vir ${ }^{(19)}$.

Os integrantes do sistema socioeducativo se encontram submetidos a modos de viver cotidiano. $M$ as a cotidianidade não é a definição de uma apreciação quantitativa. 0 dia-dia não é a soma de todos os dias em nossa existência. Significa um movimento de existência, é o como vivemos nosso dia-dia nos diferentes modos de ser no mundo(19).

Revela sua idade e que logo vai ser "de maior". A ssim, sabe que não cumprirá mais a M SE; em caso de conflito com a lei, poderá ser submetido à sentença penal.

[ ...] daqui a pouco to de maior, tenho um tio lá no presídio e ele me diz que não quer me vê por lá [ ...] (A1).

[ ...] eu to preso desde os trezeanos, claro saía, voltava [ ...] diz que não vai vim, mais vem. [ ...] vou pagar tudo e não volto mais, pra cá não [ ...] depois dos dezoito tu não vem pra cá, vai pro cadeião. Tenho um irmão lá dona, meu tio também já teve lá [ ...] (A2).

[ ...] eu vim pra cá com treze dona, vou fazer dezoito em agosto; agora sim não venho mais pra cá [ ...] ai é presídio [ ...] (A6).

A presenta certa familiaridade ao falar de presídio. 0 adolescente tem familiares que cumprem pena na penitenciária e o alertam a não ir para lá. Ele sabe que, ao fechar três anos de MSE ou ao completar os 21 anos, sua saída da unidade é compulsória.

0 adolescente se mostra no modo de ser da ambiguidade, quando diz que vivendo a MSE se sente preso e não gosta, sabe logo será maior de idade e irá realmente para prisão, no entanto, se tiver a oportunidade foge e se envolve com as drogas. Com isso pode cometer novos delitos. Então, tudo parece ter sido compreendido, quando não 0 foi. Essa ambiguidade não se estende apenas ao mundo, mas, também, a convivência como tal e até mesmo ao ser da presença para consigo mes$\mathrm{mo}^{(19)}$.

Durante o tempo de cumprimento da M SE, vai à escola para aprender algo, para arrumar algum trabal ho. Valoriza o trabalho e o estudo, mas revelam que na rua não o faziam. Entende que é preciso trabal har e pode ser uma forma de mantêlo afastado de problemas e de minimizar o sofrimento da mãe por sua causa, mas é difícil, não tem experiência e ter estado na Instituição é um problema.

[ ...] a única coisa boa éa escola. J á to lendo meu nome, na rua eu não ia estuda [ ...] a dona [ monitora] ta achando um trabalho pra mim, numa oficina, eu começo ajudando, aí ela consegue um curso [ ...] (A2).

[ ...] aprendendo alguma coisa longe das drogas? joga futebol, ir na escola [ ...] (A 3).

[ ...] vou arruma um trampo pra mim e me acomoda, a minha mãejá sofreu muito dona [ ...] aqui o cara sai, vai pro colégio, pro curso, vai todo fim de semana pra casa. Toma uma canseira, nem precisa de remédio pra dormi [ ...] (A6).

[ ...] agora que eu não tenho ninguém vou precisar trabalha né, se não quiser segui nessa vida [ ...] as dona aqui dão uma força, elas arrumam aula, curso, trabaIho. Se o cara qué, elas ajudam. eu lá fora nem queria saber de ir na aula, aqui já vou diretinho [ ...] (A 7).

[ ...] pelo menos to estudando. Capaz quelá fora eu ia ta estudando. To no curso também [ ...] (A 8).

A ocupação é um dos muitos modos de ser do adolescente no seu cotidiano, exemplificando como: ter o que fazer com alguma coisa, produzir al guma coisa, tratar e cuidar de alguma coisa, fazer desaparecer, ou deixar perder-se de alguma coisa, empreender, pesquisar, interrogar, considerar, discutir. Esses modos de serem possuem o modo de ser da ocupação. É se ocupando dos entes e das coisas do mundo em sua cotidianidade que 0 adolescente sendo infrator descobre a possibilidade de viver esse tempo junto e em-meio-ao-mundo da M SE ${ }^{(19)}$. 
0 adolescente se mostra empenhado para manter-se em conformidade com as nor mas e regras institucionais, escapando, assim, da sua historicidade autêntica. Sua adaptação ao sistema é uma necessidade para poder-ser nesse mundo, da M SE .

Procura encontrar as formas de como sair para as atividades educativas, de trabalho e de passeio familiar. Com isso ele se ocupa. E m sua circunvisão(19), relata que, após cumprir a M SE, "sai limpo", referindo-se a não ficar com registro judicial.

D estaca a rotina de estudo e trabalho no sistema, vê aí uma oportunidade. Assim, na analise das entrevistas foi possível captar a significação de ser adolescente no em-meio-a-M SE, mais uma etapa na sua historicidade, o qual se mantém ocupado.

Percebe-se que esse modo de ser junto-aosoutros, envolvido no dia-dia do sistema socioeducativo, retira-Ihes a possibilidade mais própria do ser, absorvido pela rotina do sistema. Ser-adolescente e estar-cumprindo a M SE é mais um modo de ser do impessoal. No modo de ser impessoal, todo mundo é outro e ninguém é si próprio. $\mathrm{Na}$ impessoalidade, divertimo-nos, entretemo-nos, lemos, julgamos, nivelamos a medianeidade 0 que é conveniente. A medianeidade promove 0 que se pode e deve fazer ${ }^{(19)}$.

Assim, no modo de ser cotidiano, o adolescente-sendo-infrator que cumpre a M SE se mostra como todos e não como si mesmo, visto que a padronização se impõe ou Ihe é imposta. A padronização de todas as suas possibilidades do ser exclui a presença de sua própria responsabilidade ${ }^{(19)}$. Exprime uma impessoalidade na maneira que se apresentam no dia-a-dia: como a gente e não como seu próprio eu. Portanto, no cotidiano e ocupado, o modo de ser que absorve a presença caracteriza-se no impessoal.

Então, a vivência no sistema socioeducativo poderá ser a referência necessária a um possível movimento da condição de adolescente-sendo-infrator para o ser-adolescente-de-possibilidades.

\section{CONCLUSÕES}

A investigação possibilitou dar voz aos adolescentes que cumprem M SE de semiliberdade e olhar para eles em sua singularidade. Oportunizou a compreensão do cotidiano vivido desse ser-adolescente.
Conclui-se que o adolescente está-lançado naquilo que está determinado, expresso pelo: legado de uma tradição do passado vivido pelos seus familiares, seus pares e por eles próprios antes da semi-liberdade; e pela submissão à rotina do sistema. $M$ antém-se na impessoalidade e absorvido pelo mundo e pela co-presença dos outros. U ma vez que esta no modo de ser do falatório ele mostra que não compreende a M SE e que se empenha no convívio com os outros. Ele reconhece que perde um momento singular que é a adolescência, no entanto, absorvido pelo vivido não é ele mesmo, se mostra como igual a todos os outros na impessoalidade.

D urante a MSE, vislumbra-se a possibilidade de a Enfermagem, como membro de uma equipe multiprofissional, aprimorar a assistência em unidades da FASE. No sentido de promover um desenvolvimento saudável, propor ações de promoção/ educação em saúde com vista à (re)inserção desse adolescente em sua família e na sociedade e, ainda, a prevenção de seu (re)ing resso no sistema socioeducativo. T ais ações podem ser desenvolvidas de modo individual, em consultas de enfermagem que possibilite um espaço de escuta ao adolescente. E / ou ainda de modo grupal, em que se possibilite 0 encontro entre os pares a fim de construir um espaço dialógico, que poderá se configurar uma rede de apoio, em que tenham um espaço para compartilhar experiências, desafios, medos, inseguranças, (des)esperanças. Enfim, que a Enfermagem construa com-eles estratégias de enfrentamento do cotidiano vivido dentro e fora da FA SE , a partir de suas demandas de saúde.

Acredita-se que por meio das ações sócioeducativas que possibilitem a compreensão do adolescente como ele é em seu cotidiano, impulsiona-se a construção de subsídios para um movimento da condição de adolescente-sendo-infrator para ser-adolescente-de-possibilidades. Por fim, destaca-se que, para sua reinserção social precisa de ajuda do sistema socioeducativo, mediado pelo trabal ho interdisciplinar, rede de apoio de co-responsabilidade da família, comunidade e Estado.

\section{REFERÊ NCIAS}

1 Feijó M C, Assis SG 0 contexto de exclusão social e de vulnerabilidades de jovens infratores e de suas famílias. Estud Psicol. 2004;9(1):157-66. 
2 F undação de Atendimento Sócio-E ducativo do Rio G rande do Sul. A presentação FASE [ Internet] . Porto Alegre; 2009 [ citado 2009 nov 15] . Disponível em: http:// www.fase.rs.gov.br/ arquivos/ 1190635845 A presentacao_Fase.pdf.

3 Ayres JRCM , França Junior I, Calazans GJ, Saletti Filho HC. $O$ conceito de vulnerabilidade. In: Padoin SM M, Paulo CC, Schaurich D, Fontoura VA, organizadores. Experiências interdisciplinares em aids: interfaces de uma epidemia. Santa M aria: edU F SM ; 2006. p. 43-62.

4 M artins M C, Pillon SC. A relação entre a iniciação do uso de drogas e o primeiro ato infracional entre os adolescentes em conflito com a lei. Cad Saúde Pública. 2008;24(5):1112-20.

5 Ferigollo M, Barbosa FS, Arbo E, M alysz AS, Stein AT, Barros H M T. Prevalência do consumo de drogas na FE BE M , Porto Alegre. Rev Bras Psiquiatr. 2004; 26(1):10-6.

6 Heim J, Andrade AG. Efeitos do uso o álcool e das drogas ilícitas no comportamento de adolescentes de risco: uma revisão das publicações científicas entre 1997 e 2007. Rev Psiquiatr Clín. 2008;35(Supl 1): 61-8.

7 M alhotra C, Sharma N, Saxena R, Ingle GK. Drug use among juveniles in conflict with the law. Indian J Pediatr. 2007;74(4):353-6.

8 G uimarães CF, Santos DVV, F reitas RC, A raujo RB. Perfil do usuário de crack e fatores relacionados à criminalidade em unidade de internação para desintoxicação no H ospital Psiquiátrico São Pedro de Porto Alegre (RS). Rev Psiquiatr Rio Gd Sul. 2008;30 (2):101-8.

9 B otvin GJ, G riffin KW, N ichols T D. Preventing youth violence and delinquency through a univer sal schoolbased prevention approach. Prev Sci. 2006;7(4):4038.

10 Pacheco JT B, H utz CS. Variáveis familiares preditoras do comportamento anti-social em adolescen-

\section{Endereço da autora / Dirección del autor / Author's address:}

Stela M aris de M ello Padoin U niversidade F ederal de Santa M aria

Av. Roraima, 1000, Prédio 26,

Campus U niver sitário Camobi

97115-900, Santa M aria, RS

E-mail:stelamaris_padoin@ hotmail.com tes autores de atos infracionais. Psicol T eor Pesqui. 2009;25(2):213-9.

11 Branco BM , W agner A. Os adolescentes infratores e 0 empobrecimento da rede social quando do retorno à comunidade. Ciênc Saúde Colet. 2009;14(2): 557-66.

12 Penso M A, Sudbrack M F. Envolvimento em atos infracionais e com drogas como possibilidades para lidar com o papel de filho parental. Psicol USP. 2004; 15(3):29-54.

13 Phebo L, M oura AT M S. Violência urbana: um desafio para o pediatra. J Pediatr. 2005;81(Supl 5):S189-96.

$14 \mathrm{G}$ arbarino J. Por que os adolescentes são violentos. Ciênc Saúde Colet. 2009;14(2):533-8.

15 F undação de A tendimento Sócio-E ducativo do R io Grande do Sul. Programa de execução de medidas sócio-educativas de inter nação e semiliber dade do Rio Grande do Sul (PEM SEIS) [ Internet] . Porto Alegre; 2009 [ citado 2009 nov 15]. Disponível em: http:/ / www.fase.rs.gov.br/ arquivos/ 1189084873 pemseis.pdf.

16 M CE Ihaney KB, Immele A, Smith FD, Allen JP. A ttachment organization as a moder ator of the link between friendship quality and adolescent delinquency. Attach H um D ev. 2006;8(1):33-46.

17 Lavall E, Olschowsky A, Kantorski L P. Avaliação de família: rede de apoio social na atenção em saúde mental. Rev G aúcha E nferm. 2009;30(2):198-205.

18 Ferreira VM , Tocantins FR, N ogueira M L. E nfermeiro e familiar de usuário de centro de atenção psicossocial: necessidade de saúde expressa. Rev $\mathrm{G}$ aúcha Enferm. 2009;30(2):235-41.

19 H eidegger M . Ser e tempo: partel . 6a ed. Petrópolis: Vozes; 1997.

20 Carval ho AS. M etodologia da entrevista: uma abordagem fenomenológica. $2^{2}$ ed. Rio de Janeiro: A gir; 1991.

Recebido em: 18/ 09/2010

A provado em: 17/ 08/ 2011 